\title{
Effect of Hydrochloric Acid on the Structural of Sodic-Bentonite Clay
}

\author{
Samira Bendou, Moussa Amrani* \\ Laboratory of Soft Technology, Recovering, and Sustainable Development, Faculty of Science, \\ M'Hamed Bougara University, Boumerdes, Algeria \\ Email: bendou74@yahoo.fr, moussaamrani@yahoo.fr
}

Received 5 July 2014; revised 11 August 2014; accepted 26 August 2014

Copyright (C) 2014 by authors and Scientific Research Publishing Inc.

This work is licensed under the Creative Commons Attribution International License (CC BY). http://creativecommons.org/licenses/by/4.0/

(c) (i) Open Access

\section{Abstract}

The objective of this work is to determine changes of surface properties of a bentonite after acid activation, using hydrochloric acid solutions ( $\mathrm{HCl}$ ) at room temperature. XRD, FX, FTIR, MEB, and BET analyses of the samples have been carried out to examine the structure of bentonite before and after acid activation. It is found that the raw bentonite is composed of dioctahedral montmorillonite with predominant quantity and certain amounts of quartz, albite and illite, etc. It has an cation exchange capacity (CEC) of $74.32 \mathrm{meq} / \mathrm{g}$ which allows it to be characterized as typical sodium bentonite. The changes, at low acid concentrations, are the result from from cation exchange (exchangeable cations with $\mathrm{H}^{+}$ions). Differences of surface area at high acid concentrations ( $0.25-0.4 \mathrm{M})$ were caused by structural changes and partial decomposition of the samples. Data of surface area measurements have showed that with increase of concentration of hydrochloric acid, the surface area increased. The maximum value $\left(837.11 \mathrm{~m}^{2} / \mathrm{g}\right)$ was reached by the sample activated with $0.4 \mathrm{M} \mathrm{HCl}$. By against, activation with higher concentration $(0.6 \mathrm{M})$ caused a decrease in the surface area.

\section{Keywords}

Bentonite, Sodic-Montmorillonite, Acid Activation, Cation Exchange Capacity, Surface Area

\section{Introduction}

Bentonite refers to a naturally occurring material which consists primarily of fine-grained particles, which is generally plastic at appropriate water contents and hardens when it is dried or fired [1]. Major clay minerals in bentonites are smectites, such as montmorillonite, beidellite, saponite, nontronite, and hectorite [1]-[3]. Two

*Corresponding author.

How to cite this paper: Bendou, S. and Amrani, M. (2014) Effect of Hydrochloric Acid on the Structural of Sodic-Bentonite Clay. Journal of Minerals and Materials Characterization and Engineering, 2, 404-413.

http://dx.doi.org/10.4236/jmmce.2014.25045 
types of octahedral sheets occur in smectites: the dioctahedral type, where two-thirds of the octahedral sites are occupied mainly by trivalent cations, e.g., Al (III) or Fe (III), and the trioctahedral type, with most of the sites occupied by divalent cations, e.g., Mg (II). The negative charge of the layers is balanced by hydrated exchangeable cations in the interlayers $\left(\mathrm{Ca}^{2+}, \mathrm{Mg}^{2+}\right.$, and $\left.\mathrm{Na}^{+}\right)$[4]-[7]. The variable chemical composition influences the layer charge, CEC, $\mathrm{S}_{\mathrm{BET}}$ and pore volume, which is why the clay minerals have such a broad application [8]. Bentonite clay has various applications in the protection of soil and environment. It is used to protect land from erosion, stabilization and reclamation of infertile land and landfill, soil protection from pollution, detoxification of drinking water, purification of waste water and wine technology, etc. [3] [9].

Industrial uses of bentonite powders depend on quality and quantity of their smectites and other minerals, valence and the amount of exchangeable cations. Bentonites may be used both naturally and after some physicochemical treatments, such as acid activation, ion exchange and heating according to the application areas [10] [11]. Acid-activated bentonite powders have been used in diverse applications, such as adsorbent, catalyst and bleaching earth, and also in the preparations of carbonless copy paper, electrode, pillared clay, organoclay and nanocomposites [12]-[14].

Some physicochemical properties of bentonite change considerably with acid activation. The change in the properties appears on crystallinity of its smectite, CEC, swelling, pore structure, surface area, surface acidity, decolorizing power, catalytic activity, strength, plasticity, cohesion, and compressibility as well as the chemical and mineralogical composition [15]-[20].

In this work, Algerian Na-bentonite has been activated with hydrochloric acid at room temperature for 24 hours and the resulting materials which have been obtained with different acid concentrations have been analyzed with regard to changes in their structural and textural properties. The focus of this study is the modification of bentonite with hydrochloric acid while keeping its layered structure and developing a large specific surface area as well as retaining CEC.

\section{Materials and Methods}

\subsection{Materials}

Natural bentonite clay which used in this investigation was purchased from National Company for Geological and Mining and, it was collected from Hammam Boughrara deposit which is located on the west of Algeria. The sample was purified in laboratory to remove carbonates, calcites, iron hydroxide and organic metals. It was dispersed in distilled water and the clay fraction $(=0.74 \mathrm{~mm})$ was recovered by centrifugation, dried at $105^{\circ} \mathrm{C}$ for 24 hours, and stored in tightly closed plastic bottles for use in the experiments.

The hydrochloric acid $(\mathrm{HCl})\left(98 \%, \mathrm{~d}=1.98 \mathrm{~g} / \mathrm{cm}^{3}\right)$ and other used chemicals are of analytical grade. They were supplied by Merck Chemical Company.

\subsection{Acid Activation}

The bentonite was prepared for activation by air-drying and grinding to a particle size of $0.075 \mathrm{~mm}$. Twenty (20) $\mathrm{g}$ of the prepared sample was weighed into flask $(1000 \mathrm{ml}$ capacity) and $400 \mathrm{ml}$ of hydrochloric acid solution was added. The resulting suspension was stirred at room temperature for $24 \mathrm{~h}$. At the end of the experimental duration, the resulting slurry was poured into a Buchner funnel to separate the acid and bentonite. The residual bentonite was washed several times with distilled water until it was released from $\mathrm{Cl}^{-}$against $5 \% \mathrm{AgNO}_{3}$ solution. After drying them at $105^{\circ} \mathrm{C}$ for $4 \mathrm{~h}$, the activated samples were stored in tightly closed plastic bottles. The activation process repeated with varying acid concentrations of $0.05-0.6 \mathrm{M}$ of $\mathrm{HCl}$.

\subsection{Instrumentation}

The elemental analysis of samples was conducted by X-ray fluorescence (XRF) on PHILIPS PW 1480 spectrometer that has used a dispersive technical wave length. The X-ray diffraction (XRD) data of natural and acid activated samples were obtained by a SIEMENS D 5000 difractometer equipped with graphic mono-chromator $\mathrm{CuK} \alpha$ radiation and a fixed power source $(40 \mathrm{KW}, 40 \mathrm{~mA})$ was used. The scan rate was $0.5^{\circ}(2 \theta) \mathrm{min}^{-1}$. Before chemical analysis, each sample which was dried at $105^{\circ} \mathrm{C}$ for $4 \mathrm{~h}$ was heated at $1000^{\circ} \mathrm{C}$ for $2 \mathrm{~h}$, and the decrease in mass was taken as the loss on ignition (LOI).

The FT-IR spectra has been recorded with FT-IR Spectrophotometer Model 4400 (Shimadzu Corporation, 
Japan) with $1 \mathrm{~cm}^{-1}$ resolution within the range $400-4000 \mathrm{~cm}^{-1}$. Solid clay was mixed with $\mathrm{KBr}$ in 1:10 ratio. The mixture was grinded till becoming very fine powder. The fine powder was pressed under 10 ton pressure into pellet. The Infrared spectra were obtained from solid samples and $\mathrm{KBr}$ pellets.

The CEC of samples is determined by three chloride cobalt hexanamine $\left[\mathrm{Cl}_{3} \mathrm{Co}\left(\mathrm{NH}_{3}\right)_{6}\right]$ method at pH 7.0. The mixtures of three chloride cobalt hexanamine with bentonite sample have been kept at room temperature during $1 \mathrm{~h}$ under stirring. After centrifugation, the supernatant was dosed calorimetrically at $\lambda_{\max }=470 \mathrm{~nm}$, the amounts of adsorbed at flocculation point, referred to $100 \mathrm{~g}$ of clay .These values allowed the determination of both CEC.

The specific surface area was determined using the adsorption and desorption nitrogen isotherms, at liquid nitrogen temperature of $196^{\circ} \mathrm{C}$. Before measurement, the sample was degassed at $120^{\circ} \mathrm{C}$ and vacuumed for more than 24 hours. Analysis of results has involved the determination of specific surface area of the sample using the BET equation.

Scanning electron microscopy (SEM) of the solid catalysts was carried out at $15 \mathrm{~kW}$ using a Jeol scanning electron microscope, model JSM-630LV. Each sample specimen was deposited on an aluminium stub and gold sputtered prior to analysis by SEM.

\section{Results and Discussions}

\subsection{Chemical Composition}

The chemical analyses of the natural and acid-activated bentonite powders are given in Table 1, as the mass in \% of metal oxides. The bulk chemical analysis (wt\%) of the natural bentonite sample is: $\mathrm{SiO}_{2}, 58.32 ; \mathrm{Al}_{2} \mathrm{O}_{3}, 15.32$; $\mathrm{Fe}_{2} \mathrm{O}_{3}$, 2.23; MgO, 3.21; $\mathrm{CaO}, 0.95 ; \mathrm{Na}_{2} \mathrm{O}, 1.89 ; \mathrm{K}_{2} \mathrm{O}, 1.19 ; \mathrm{TiO}_{2}, 0.15 ; \mathrm{S}_{2} \mathrm{O}_{3}, 0.1 ; \mathrm{P}_{2} \mathrm{O}_{5}, 0.11 ; \mathrm{MnO}_{2}, 0.09$ and loss on ignition (L.O.I.); $13.73 \mathrm{SiO}_{2}$ and $\mathrm{Al}_{2} \mathrm{O}_{3}$ are the major constituents of the clay with other oxides present in trace amounts. The results of Table 1 also show the changes in the chemical composition and the ratio of Si/(Al $+\mathrm{Fe}+\mathrm{Mg}$ ) of the bentonite clay as a function of acid concentration. By increasing the hydrochloric acid concentration from 0.05 to $0.6 \mathrm{M}$, there was an increase in $\mathrm{SiO}_{2}$ content in bentonites, but the increase was more at higher acid concentration. The same behavior is observed in the ratio of $\mathrm{Si} /(\mathrm{Al}+\mathrm{Fe}+\mathrm{Mg}$ ) which was increased in bentonite until treatment with $0.6 \mathrm{M}$. Bentonite activation with hydrochloric acid has caused an increase of the $\mathrm{SiO}_{2}$ content due to remobilization of octahedral cations [21]-[23]. Octahedral cations have shifted into the solution while the silicon, owning to its insolubility, remained and its content has increased with the increase of $\mathrm{HCl}$ concentration. After the treatment with $0.6 \mathrm{M}$, the $\mathrm{Al}_{2} \mathrm{O}_{3}, \mathrm{Fe}_{2} \mathrm{O}_{3}$, and $\mathrm{MgO}$ content have decreased by $48.56 \%, 66.36 \%$, and $84.42 \%$ respectively. Table 2 shows the changes of the CEC, the specific surface area and the bulk density of the bentonite clay as the function of acid concentration. With an increase in concentration of

Table 1. Chemical analysis and specific surface area of the natural, and acid activated bentonite samples.

\begin{tabular}{|c|c|c|c|c|c|c|}
\hline \multirow{3}{*}{ Component (\%) } & \multicolumn{6}{|c|}{ Bentonite } \\
\hline & \multirow{2}{*}{ Untreated } & \multicolumn{5}{|c|}{ Treated with different concentrations of $\mathrm{HCl}$} \\
\hline & & $0.05 \mathrm{M}$ & $0.15 \mathrm{M}$ & $0.25 \mathrm{M}$ & $0.4 \mathrm{M}$ & $0.6 \mathrm{M}$ \\
\hline $\mathrm{SiO}_{2}$ & 58.32 & 59.66 & 61.32 & 63.10 & 65.32 & 69.66 \\
\hline $\mathrm{Al}_{2} \mathrm{O}_{3}$ & 15.82 & 14.85 & 13.24 & 11.85 & 9.79 & 7.88 \\
\hline $\mathrm{Fe}_{2} \mathrm{O}_{3}$ & 2.63 & 1.76 & 1.50 & 1.21 & 1.04 & 0.75 \\
\hline $\mathrm{Na}_{2} \mathrm{O}$ & 1.89 & 1.69 & 1.49 & 0.60 & 0.20 & 0.10 \\
\hline $\mathrm{K}_{2} \mathrm{O}$ & 1.19 & 1.90 & 1.85 & 1.65 & 1.83 & 1.82 \\
\hline $\mathrm{MgO}$ & 3.31 & 3.19 & 2.80 & 1.86 & 1.60 & 0.50 \\
\hline $\mathrm{CaO}$ & 0.95 & 0.70 & 0.50 & 0.15 & 0.10 & 0.05 \\
\hline $\mathrm{TiO}_{2}$ & 0.15 & 0.12 & 0.11 & 0.10 & 0.07 & 0.07 \\
\hline $\mathrm{S}_{2} \mathrm{O}_{3}$ & 0.10 & 0.11 & 0.10 & 0.10 & 0.10 & 0.07 \\
\hline $\mathrm{P}_{2} \mathrm{O}_{5}$ & 0.11 & 0.10 & 0.11 & 0.11 & 0.10 & 0.10 \\
\hline $\mathrm{MnO}_{2}$ & 0.09 & - & - & - & - & - \\
\hline L.O.I. & 13.73 & 14.84 & 15.35 & 16.55 & 17.78 & 18.21 \\
\hline Total & 98.29 & 98.92 & 98.37 & 97.28 & 97.93 & 99.27 \\
\hline $\mathrm{Si} /(\mathrm{Al}+\mathrm{Fe}+\mathrm{Mg})$ & 2.81 & 2.99 & 3.49 & 4.23 & 5.25 & 7.63 \\
\hline
\end{tabular}


Table 2. Effect of acid concentration on the bentonite surface are, mass percent of $\left(\mathrm{Al}_{2} \mathrm{O}_{3}+\mathrm{Fe}_{2} \mathrm{O}_{3}+\mathrm{MgO}\right)$, bulk density, and CEC.

\begin{tabular}{cccccccc}
\hline & \multicolumn{7}{c}{ Bentonite } \\
\cline { 3 - 7 } Component & Untreated & \multicolumn{5}{c}{ Treated with different concentrations of HCl } \\
\cline { 3 - 7 } & & $0.05 \mathrm{M}$ & $0.15 \mathrm{M}$ & $0.25 \mathrm{M}$ & $0.4 \mathrm{M}$ & $0.6 \mathrm{M}$ \\
\hline $\mathrm{S}_{\mathrm{BET}}\left(\mathrm{m}^{2} / \mathrm{g}^{1}\right)$ & 508.27 & 580.32 & 600.57 & 715.64 & 837.11 & 544.37 \\
Mass percent of $\left(\mathrm{Al}_{2} \mathrm{O}_{3}+\mathrm{Fe}_{2} \mathrm{O}_{3}+\mathrm{MgO}\right)(\%)$ & 21.76 & 19.80 & 17.54 & 14.92 & 12.43 & 9.13 \\
Bulk density $\left(\mathrm{kg} / \mathrm{m}^{3}\right)$ & 1026.9 & 997.7 & 976.3 & 950.1 & 896.5 & 927.6 \\
CEC (méq $/ \mathrm{g})$ & 74.32 & 70.56 & 62.33 & 46.75 & 40.15 & 70.56 \\
\hline
\end{tabular}

hydrochloric acid, the activated samples have showed a gradual increase in the surface area until treatment with $0.4 \mathrm{M} \mathrm{HCl}$. In treatment with $0.6 \mathrm{M} \mathrm{HCl}$, a decrease of surface area was observed in comparison with the surface area of the sample treated with $0.4 \mathrm{M} \mathrm{HCl}$. This increase in surface area is as a result of the leaching of the octahedral cations from the inter layer of the samples, and this shows a relationship between the surface area and the amount of $\mathrm{Al}_{2} \mathrm{O}_{3}+\mathrm{Fe}_{2} \mathrm{O}_{3}+\mathrm{MgO}$ in the samples, and the generation of micro-porosity during the activation process [24]. The decrease observed at higher acid concentrations can be explained by the process of passivation [25]. The octahedral sheet destruction passes the cations into the solution, while the silica generated by the tetrahedral sheet remains in the solids, due to its insolubility. Pesquera et al. [25] suggesting that this free silica which is generated by the initial destruction of the tetrahedral sheet is polymerized by the effect of such high acid concentrations and is deposited on the undestroyed silicate fractions, protecting it from further attack and, thereby, resulting to a decreased surface area. The results of the bulk density measurement of clay show a decrease in density as acid concentration in bentonite-acid mixture has increased. According to this trend, bentonite clay property is changed with the acid activation progresses.

The CEC values of the samples have also displayed similar behavior. With the increase of concentration of $\mathrm{HCl}$, the samples have showed a gradual decrease in CEC until treatment with $0.4 \mathrm{M} \mathrm{HCl}$. In treatment with 0.6 $\mathrm{M} \mathrm{HCl}$, an increase of the CEC has been observed in comparison with the CEC of sample treated with $0.4 \mathrm{M}$ $\mathrm{HCl}$ and this can also be explained by the process of passivation [25] [26].

The variations of the relative content of metals $\left(\mathrm{M} / \mathrm{M}_{0}\right)$ in the bentonite with hydrochloric acid $(\mathrm{HCl})$ are given in Figure 1 in which $\mathrm{M}_{0}$ and $\mathrm{M}$ are the mass in \% of the element oxides in the natural and acid-activated bentonite samples. The relative contents of the undissolved elements in the bentonite increase in the order of $\mathrm{Ca}^{2+}, \mathrm{Na}^{+}, \mathrm{Fe}^{3+}, \mathrm{Mg}^{2+}, \mathrm{Ti}^{4+}, \mathrm{Al}^{3+}, \mathrm{S}^{3+}, \mathrm{P}^{5+}, \mathrm{Si}^{4+}$, and $\mathrm{K}^{+}$by the increase in $\mathrm{HCl}$ molarities. The $\mathrm{K}^{+}$cations between 2:1 layers of illite and the $\mathrm{Si}^{4+}$ cations at tetrahedral sites of smectite and illite are not dissolved by acid activation. The increase in relative contents of these cations depends on the dissolution of other cations by the activation. The relative $\mathrm{S}^{3+}, \mathrm{P}^{5+}$ content decreases slowly by the acid activation. It was discussed that the $\mathrm{S}^{3+}$, $\mathrm{P}^{5+}$ cations are located either on octahedral sites or tetrahedral sites. The increase in the relative content of $\mathrm{S}^{3+}, \mathrm{P}^{5+}$ shows that these cations are located most probably at the tetrahedral sites in the 2:1 layers of smectite similar to $\mathrm{Si}^{4+}$ cations.

Dissolution (\%) of the exchangeable cations $\mathrm{Ca}^{2+}, \mathrm{K}^{+}$and $\mathrm{Na}^{+}$from the bentonite structure is calculated and shown in Figure 2. It is expected that a significant amount of these cations is removed after leaching with $0.1 \mathrm{M}$ acid concentration. Dissolution of these cations remains almost constant by continuing the activation process with higher acid concentrations. However, a considerable amount of these elements is still found in the activated bentonite due to the presence of impurities, mainly feldspar that has calcium, sodium and potassium, and it is resistant to acid attack [27] [28]. It is presumed that at low acid concentration the attack on the structure is weak and that the exchangeable cations replaced by $\mathrm{H}^{+}$ions are few [29].

\subsection{Mineralogical Composition}

The XRD patterns of the samples are given in Figure 3. The bentonite contains a sodium-richmontmorillonite (NaM) with the $\mathrm{d}(001)$ value of $15.56 \AA$ that is the dominant montmorillonite mineral which seems well crystallized in the sample. Other minerals were found to be quartz, orthodase, albite, and illite. Leaching of the sample 


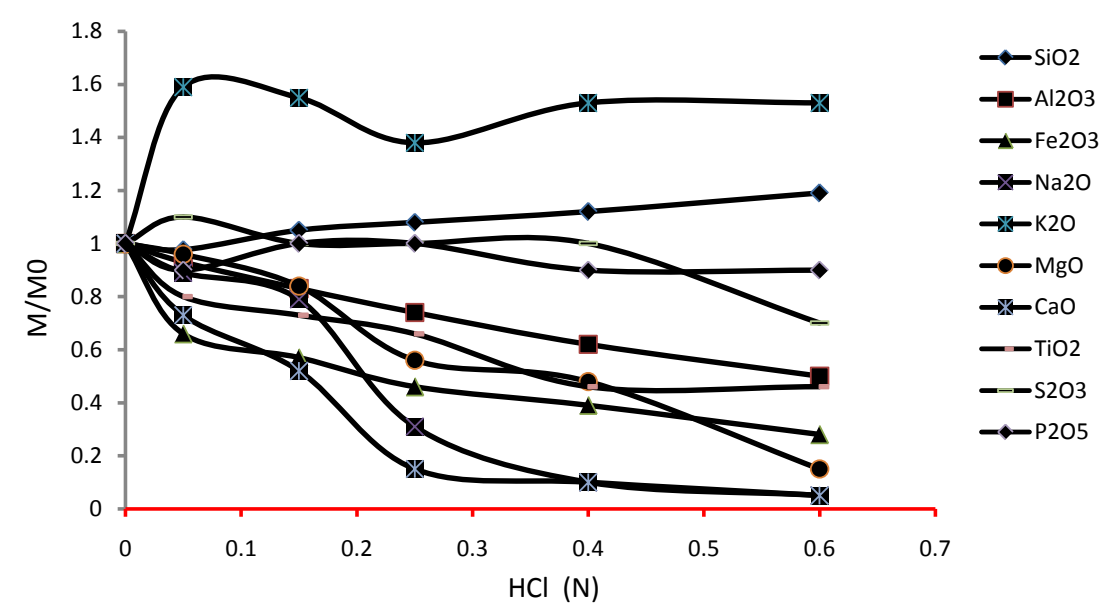

Figure 1 . The changes in relative metal contents $\left(M / M_{0}\right)$ of the bentonite powders by $\mathrm{HCl}(\mathrm{M})$ in activation.

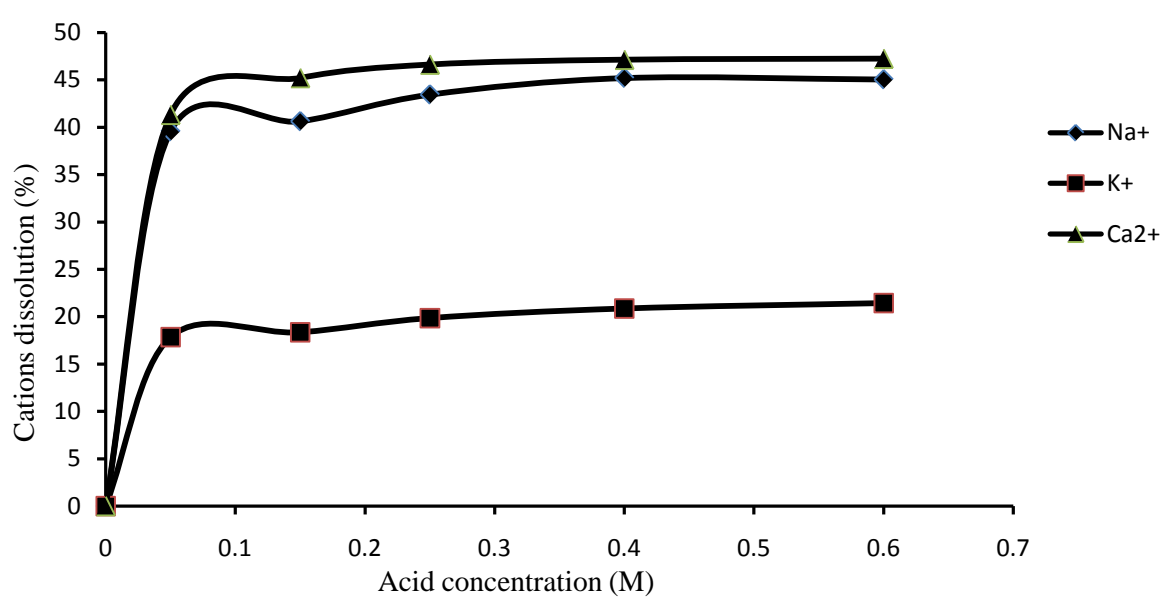

Figure 2. Cation dissolution at different acid concentrations.

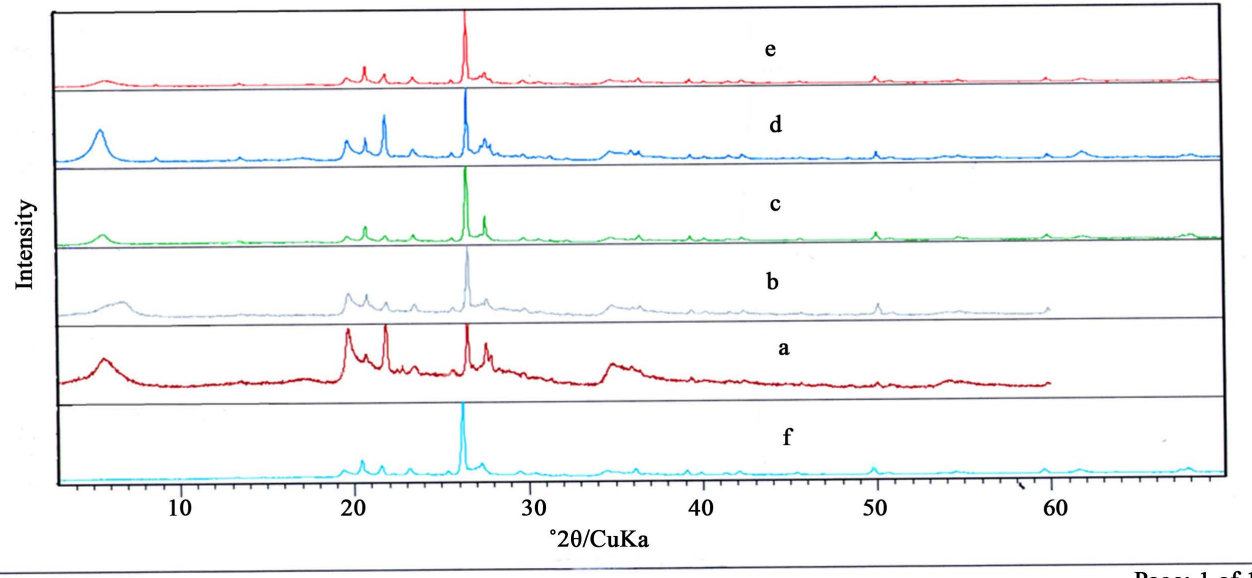

Figure 3. XRD patterns of untreated bentonite (a), and activated with chlorhydric acid at different concentrations: (b) $0.05 \mathrm{M}$; (c) 0, $15 \mathrm{M}$; (d) $0.25 \mathrm{M}$; (e) $0.40 \mathrm{M}$; (f) $0.6 \mathrm{M}$. 
with chlorhydric acid produces important mineralogical changes which can be seen from XRD patterns of Figures $3(b)$-(f). The most pronounced modification occurs in the montmorillonite $d(001)$ peak (the first peak appearing at $2 \theta$ angle about $4^{\circ}$ ) which shows a reduction in intensity as a result of acid attack. For concentrations of hydrochloric acid $0.05 \mathrm{M}$ and $0.25 \mathrm{M}$ the corresponding peaks are $\mathrm{d}(002)=12.71 \AA$, and $\mathrm{d}(005)=15.80 \AA$ respectively. It is clearly observed that hydronium cations can intercalate into the interlayer spacing of the sodic-bentonite by the mechanism of cation exchange, without the loss of layer structure. The hydrophilized bentonite exhibits rather broad diffraction peaks $\mathrm{d}(005)=15 \AA$ at $0.4 \mathrm{M}$ of hydrochloric acid concentration.

The reduction in intensity and increase in the width of $\mathrm{d}(001)$ peak indicate that the crystallinity of the $\mathrm{NaM}$ is considerably affected by acid activation. This means that the process favours the production of amorphous phase by decomposing montmorillonite crystalline structure [30]. This effect is more pronounced for activations with $0.6 \mathrm{M}$ acid solutions, where the cebatite clay produced at $\mathrm{d}(006)=10 \AA$. Similar results were already described in the literature [16]. It can be also observed that the characteristic peaks corresponding to quartz, orthodase, albite, and illite minerals disappear after acid activation under relatively mild conditions.

\subsection{FTIR Characterization}

The FTIR spectra of the untreated and hydrochloric acid treated bentonite samples in the wave number range of $4000-500 \mathrm{~cm}^{-1}$ are shown in Figure 4. The spectrum of the untreated bentonite exhibits absorption bands at 3422 and $1638 \mathrm{~cm}^{-1}$ this is assigned to the stretching and bending vibrations of the $\mathrm{OH}$ groups for the water molecules adsorbed on the clay surface, and a band at $3621 \mathrm{~cm}^{-1}$ which represents the stretching vibration of the hydroxyl groups coordinated to octahedral $\mathrm{Al}^{3+}$ cations [27] [31]. The spectra show sharp band vibrations in the region between 1000 and $400 \mathrm{~cm}^{-1}$ it is described in earlier papers [32] [33]. Namely, the most intensive band at $1035 \mathrm{~cm}^{-1}$ in the spectra of untreated bentonite was attributed to Si-O stretching vibrations (in-plane) of the tetrahedral sheets, whereas the bands around 521 and $466 \mathrm{~cm}^{-1}$ are ascribed to Si-O-Al (where Al is the octahedral cation) and Si-O-Si bending vibrations, respectively [34]. The intensive bands near $916 \mathrm{~cm}^{-1}, 845 \mathrm{~cm}^{-1}$, and 521 $\mathrm{cm}^{-1}$ attributed to $\mathrm{Al}-\mathrm{Mg}-\mathrm{OH}, \mathrm{Al}-\mathrm{Al}-\mathrm{OH}$ and $\mathrm{Al}-\mathrm{OH}-\mathrm{O}-\mathrm{Si}$ stretching vibration respectively.

The raw bentonite spectrum also contains a band between 796 and $693 \mathrm{~cm}^{-1}$ which are attributed to orthodase and quartz respectively [27] [35]. FTIR spectra of Figures 4(b)-(f) show the decreasing intensity as a result of acid activation bentonite which reflects the leaching of octahedral cations, such as $\mathrm{Al}^{3+}$ and $\mathrm{Mg}^{2+}$ from the bentonite structure. The reduction of the content of the octahedral cations is accompanied by a decrease of both $\mathrm{OH}$ bending vibrations at 916 and $845 \mathrm{~cm}^{-1}$ [36].

The FTIR result is in clear agreement with the XRF and XRD studies which indicate sequential degradation of the clay sheet upon acid treatment.

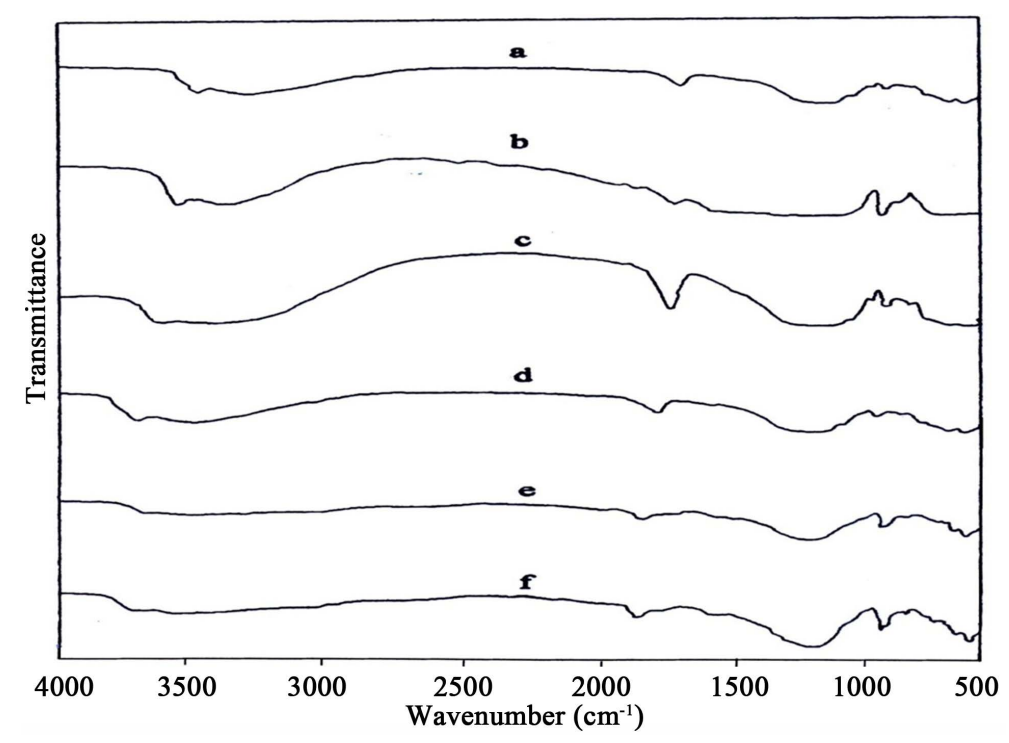

Figure 4. FTIR spectrum of the natural (a) and, acidactivated bentonite samples (b)-(f)). 


\subsection{SEM Analysis}

Scanning electron micrograph of bentonite samples was obtained and presented to an enlarging equal to $6000 \times$ in the Figure 5. The micrograph of the untreated bentonite can be clearly observed from the Figure 5(a) which shows that the size bentonite grains is different, and their diameter is located between $29 \mu \mathrm{m}$ and $126 \mu \mathrm{m}$, and the aggregate mass of irregularly shaped particles that appeared to have been formed by several flaky particles stacked together in form of agglomerates. The micro-graphs of acid treated bentonite indicate the disaggregation and decrease in size of clay structure by acid treatment Figures 5(b)-(f). When compared with Figure 5(a), it showed a clear distinction on visual analysis the microstructural differences. The diameter of particles acid treated bentonite varied from $250 \mu \mathrm{m}$ to $780 \mu \mathrm{m}$. These variations, thus, have led to decrease in the density of acid treated bentonite as the particulate volume automatically increases and therefore decreases the specific
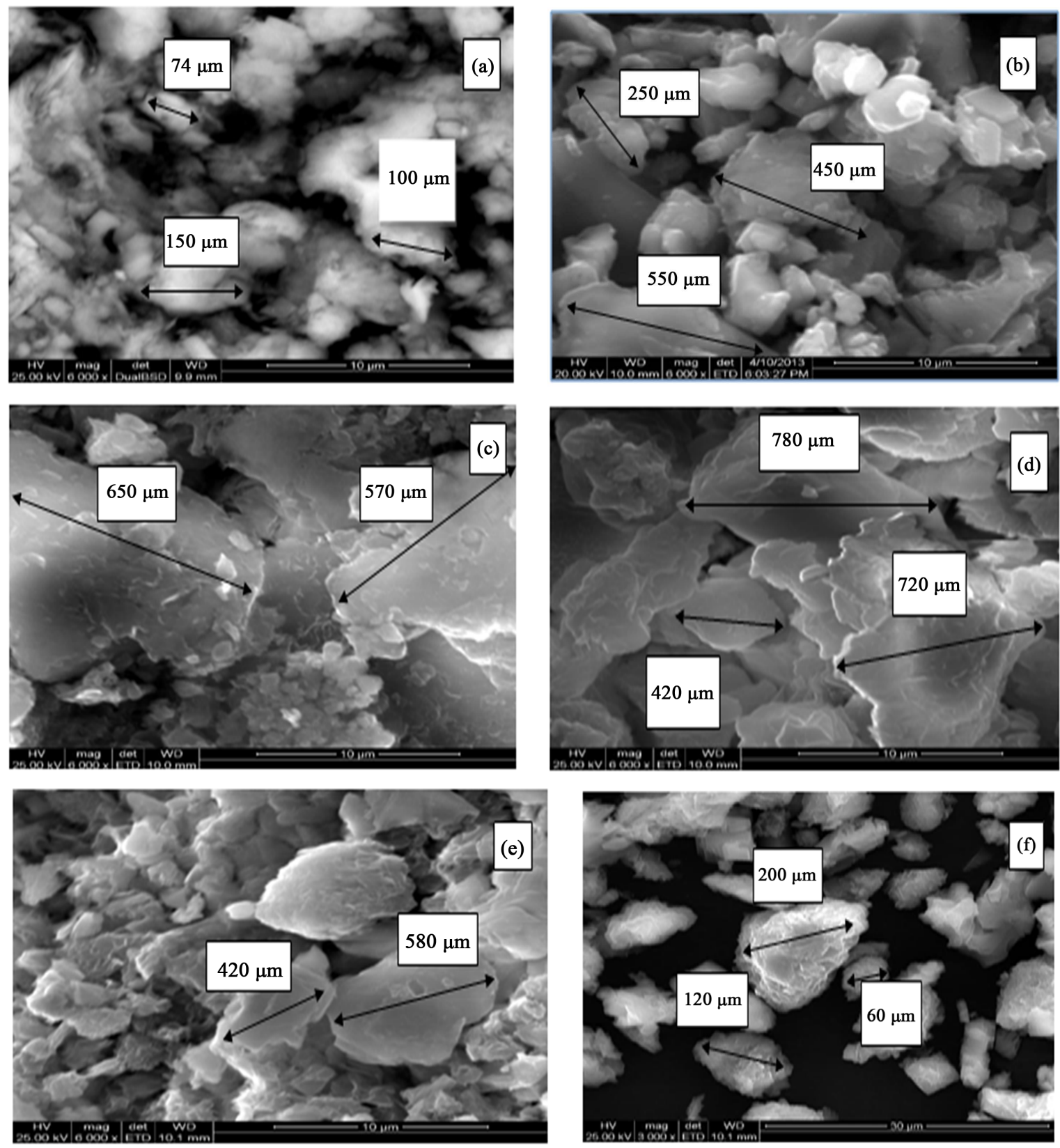

Figure 5. Scanning electronic micrographs of untreated bentonite (a), and activated with chlorhydric acid under different concentrations: (b) $0.05 \mathrm{M}$; ( c) $0.15 \mathrm{M}$; (d) $0.25 \mathrm{M}$; (e) $0.4 \mathrm{M}$; (f) $0.6 \mathrm{M}$. 
gravity. According to Amari et al. [23], in the line with the previous results reported by Morgan et al. and Kheok and Lim [36] [37], state that the surface increases with the increase of acid concentration to the optimal value, beyond this acid concentrations the surface decreases. The SEM micrograph of activated bentonite with $\mathrm{HCl}$ 0.6 N shows the diminution of proportions of the different grains of size located between $60 \mu \mathrm{m}$ and 200 $\mu \mathrm{m}$. The edges of the sheets are opened and separated, so the separation of layers are explained by the phenomenon of hydrofobia with the migration of hydronium ions towards the surface and the transformation of their crystal lattice (Figure 5(f)).

\section{Conclusions}

The effect of hydrochloric acid activation on the structure of bentonite clay has been successfully investigated. Natural bentonite used is sodium-richmontmorillonite clay as confirmed by chemical composition and the XRD analysis. Acid treatment has partially altered the structure of the montmorillonite. The acid concentration plays an important role in the activation step which has been confirmed by XDR, FTIR, BET, and SEM analyses. This has led to increasing a specific surface area of bentonite. The increase of acid concentration up to $0.1 \mathrm{M}$ has caused the increase of exchangeable cation dissolution after which it has remained almost constant.

The XRD results have pointed out that the activation has affected mainly $\mathrm{d}(001)$ (basal) reflections and has caused more changes in the interval between $0^{\circ}$ and $40^{\circ}$ of $2 \theta$ due to the decomposition of the structure and the deposition of amorphous silica. The intensities of the basal montmorillonite reflections (15.56 [ $\AA$ ] ) have been affected by acid activation. Acid-treated bentonites have greater $\mathrm{SiO}_{2}$ contents and smaller contents of $\mathrm{Al}_{2} \mathrm{O}_{3}$, $\mathrm{Fe}_{2} \mathrm{O}_{3}, \mathrm{MgO}$ and $\mathrm{CaO}$ than the natural bentonite. The activated bentonite samples have contained substantially coarser particles than the original bentonite.

\section{References}

[1] Stephen, G. and Martin, R.T. (1995) Definition of Clay and Clay Minerals: Joint Report of the Aipea Nomenclature and CMS Nomenclature Committees. Clay and Clay Minerals, 43, 255-256. http://dx.doi.org/10.1346/CCMN.1995.0430213

[2] Grim, R.E. and Güven, N. (1978) Bentonites, Geology, Mineralogy, Properties and Uses, Development in Sedimentology. Vol. 24, Elsevier, Amsterdam.

[3] Murray, H.H. (1991) Some Application of Clay Minerals. Applied Clay Science, 5, 379-395. http://dx.doi.org/10.1016/0169-1317(91)90014-Z

[4] Pauling, L. (1967) The Nature of the Chemical Bond. Cornell University Press, New York.

[5] Murray, H.H. (2000) Traditional and New Applications for Kaolin, Smectite Andpalygorskite: A General Overview. Applied Clay Science, 17, 207-221. http://dx.doi.org/10.1016/S0169-1317(00)00016-8

[6] Ayari, F., Srasra, E. and Trabelsi-Ayadi, M. (2005) Characterization of Bentonitic Clays and Theiruse as Adsorbent. Desalination, 185, 391-397. http://dx.doi.org/10.1016/j.desal.2005.04.046

[7] Murray, H.H. (1999) Applied Clay Mineralogy Today and Tomorrow. Clay Miner, 34, 39-49. http://dx.doi.org/10.1180/000985599546055

[8] Christidis, G.E., Scott, P.W. and Dunham, A.C. (1997) Acid Activation and Bleaching Capacity of Bentonitesfrom the Islands of Milos and Chios, Aegean, Greece. Applied Clay Science, 12, 329-347. http://dx.doi.org/10.1016/S0169-1317(97)00017-3

[9] Joshi, R.C., Achari, G., Horfield, D. and Nagaraj, T.S. (1994) Effect of Heat Treatment on Strength of Clays. Journal of Geotechnical Engineering, 120, 1080-1088, http://dx.doi.org/10.1061/(ASCE)0733-9410(1994)120:6(1080)

[10] Juang, R.-S., Lin, S.-H. and Tsao, K.-H. (2002) Mechanism of the Sorption of Phenols from Aqueous Solutions into Surfactant-Modified Montmorillonite. Journal of Colloid and Interface Science, 254, 234-241. http://dx.doi.org/10.1006/jcis.2002.8629

[11] Noyan, H., Önal, M. and Sarikaya, Y. (2007) The Effect of Sulfuric Acid Activation on Crystallinity, Surface Area, Porosity, Surface Acidity and Bleaching Power of a Bentonite. Food Chemistry, 105, 156-163. http://dx.doi.org/10.1016/j.foodchem.2007.03.060

[12] Hassan, M.S. and Abdel-Khalek, N.A. (1998) Beneficiation and Applications of an Egyptian Bentonite. Applied Clay Science, 13, 99-115. http://dx.doi.org/10.1016/S0169-1317(98)00021-0

[13] Jovanovic, N. and Janackovic, J. (1991) Pore Structure and Adsorption Properties of an Acid Activated Bentonite. Applied Clay Science, 6, 59-68. http://dx.doi.org/10.1016/0169-1317(91)90010-7 
[14] Komadel, P., Schmidt, D., Madejova, J. and Cicel, B. (1990) Alteration of Smectites by Treatments with Hydrochloric Acid and Sodium Carbonate Solutions. Applied Clay Science, 5, 113-122. http://dx.doi.org/10.1016/0169-1317(90)90017-J

[15] Banat, F.A., Al-Bashir, B., Al-Asheh, S. and Hayajneh, O. (2000) Adsorption of Phenol by Bentonite. Environmental Pollution, 107, 391-398. http://dx.doi.org/10.1016/S0269-7491(99)00173-6

[16] Tyagi, B., Chudasama, C.D. and Jasra, R.V. (2006) Determination of Structural Modification in Acid Activated Montmorillonite Clay by FT-IR Spectroscopy. Spectrochimica Acta Part A, 64, 273-278.

[17] Van Olphen, H. and Fripiat, J.J. (1979) Data Handbook for Clay Materials and Other Non-Metallic Minerals. Pergamon Press, Oxford.

[18] Novak, I. and Cicel, B. (1978) Dissolution of Smectites in Hydrochloric Acid: II Dissolution Rate as a Function of Crystallochemical Composition. Clays and Clay Minerals, 26, 341-344.

[19] Önal, M., Sarıkaya, Y. and Alemdaroğlu, T. (2002) The Effect of Acid Activation on Some Physicochemical Properties of a Bentonite. Turkish Journal of Chemistry, 26, 409-416.

[20] Park, S.J., Seo, D.I. and Lee, J.R. (2002) Surface Modification of Montmorillonite on Surface Acid-Base Characteristics of Clay and Thermal Stability of Epoxy/Clay Nanocomposites. Journal of Colloid and Interface Science, 251, 160-165. http://dx.doi.org/10.1006/jcis.2002.8379

[21] Venaruzzo, J.L., Volzone, C., Rueda, M.L. and Ortiga, J. (2002) Modified Bentonitic Clay Minerals as Adsorbents of $\mathrm{CO}, \mathrm{CO}_{2}$ and $\mathrm{SO}_{2}$ Gases. Microporous and Mesoporous Materials, 56, 73-80. http://dx.doi.org/10.1016/S1387-1811(02)00443-2

[22] Carrado, K.A. and Komadel, P. (2009) Bentonites-Versatile Clays: Acid Activation of Bentonites and Polymer-Clay Nanocomposites. Elements, 5, 111-116.

[23] Amari, A., Chlendi, M., Gannouni, A. and Bellagi, A. (2010) Optimised Activation of Bentonite for Toluene Adsorption. Applied Clay Science, 47, 457-461. http://dx.doi.org/10.1016/j.clay.2009.11.035

[24] Diaz, F.C. and Sanctos, P.S. (2001) Studies on the Acid Activation of Brazilian Smectitic Clays. Química Nova, 24, 345-353.

[25] Pesquera, C., Gonzalez, F., Benito, I., Blanco, C., Mendioroz, S. and Pajares, J. (1992) Passivation of a Montmorillonite by the Silica Created in Acid Activation. Journal of Materials Chemistry, 2, 907-912. http://dx.doi.org/10.1039/jm9920200907

[26] Temuujin, J., Jadamobaa, T., Burmaa, G., Erdenechimeg, S., Amarsanaa, J. and Mackenzie, K.J.D. (2004) Characterization of Acid Activated Montmorillonite from Tuulant (Mongolia). Ceramics International, 30, 251-255. http://dx.doi.org/10.1016/S0272-8842(03)00096-8

[27] Önal, M. and Sarikaya, Y. (2007) Preparation and Characterization of Acid-Activated Bentonite Powders. Powder Technology, 172, 14-18. http://dx.doi.org/10.1016/j.powtec.2006.10.034

[28] Kashani Motlagh, M.M., Youzbashi, A.A. and Amiri Rigi, Z. (2011) Effect of Acid Activation on Structural and Bleaching Properties of Bentonite. Iranian Journal of Materials Science and Engineering, 8, 50-56.

[29] Zorica, P.T., Svetlana, B.A., Biljana, M.B., Vesna, A.P., Aleksandar, R.Đ. and Svjetlana, B.C. (2011) Modification of Smectite Structure by Sulphuric Acid and Characteristics of the Modified Smectite. Journal of Agricultural Sciences, 56, 25-35.

[30] Kumar, P., Jasra, R.V. and Bhat, T.S.G. (1995) Evolution of Porosity and Surface Acidity in Montmorillonite Clay on Acid Activation. Industrial \& Engineering Chemistry Research, 34, 1440-1448. http://dx.doi.org/10.1021/ie00043a053

[31] Emmerich, K., Madsen, F.T. and Kahr, G. (1999) Dehydroxylation Behavior of Heat-Treated and Steam-Treated Homoionic CIS-Vacant Montmorillonites. Clays and Clay Minerals, 47, 591-604. http://dx.doi.org/10.1346/CCMN.1999.0470506

[32] Steudel, A., Batenburgm, L.F., Fisher, H.R., Weidler, P.G. and Emmerich, K. (2009) Alteration of Swelling Clays by Acid Treatment. Applied Clay Science, 44, 105-115. http://dx.doi.org/10.1016/j.clay.2009.02.002

[33] Madejová, J., Bujdák, J., Janek, M. and Komadel, P. (1998) Comparative FT-IR Study of Structural Modifications during Acid Treatment of Dioctahedral Smectites and Hectorite. Spectrochimica Acta Part A, 54, 1397-1406.

[34] Madejovà, J. (2003) FTIR Techniques in Clay Mineral Studies. Vibrational Spectroscopy, 31, 1-10. http://dx.doi.org/10.1016/S0924-2031(02)00065-6

[35] Kooli, F. and Liu, Y. (2013) Chemical and Thermal Properties of Organoclays Derived from Highly Stable Bentonite in Sulfuric Acid. Applied Clay Science, 83-84, 349-356. http://dx.doi.org/10.1016/j.clay.2013.07.022

[36] Morgan, D.A., Shaw, D.B., Sidebottom, T.C., Soon, T.C. and Taylor, R.S. (1985) The Function of Bleaching Earths in 
the Processing of Palm, Palm Kernel and Coconut Oils. Journal of the American Oil Chemists' Society, 62, 292-299. http://dx.doi.org/10.1007/BF02541394

[37] Kheok, S.C. and Lim, E.E. (1982) Mechanism of Palm Oil Bleaching by Montmorillonites Clay Activated at Various Acid Concentrations. Journal of the American Oil Chemists’ Society, 59, 129-131.

http://dx.doi.org/10.1007/BF02662259 
Scientific Research Publishing (SCIRP) is one of the largest Open Access journal publishers. It is currently publishing more than 200 open access, online, peer-reviewed journals covering a wide range of academic disciplines. SCIRP serves the worldwide academic communities and contributes to the progress and application of science with its publication.

Other selected journals from SCIRP are listed as below. Submit your manuscript to us via either submit@scirp.org or Online Submission Portal.
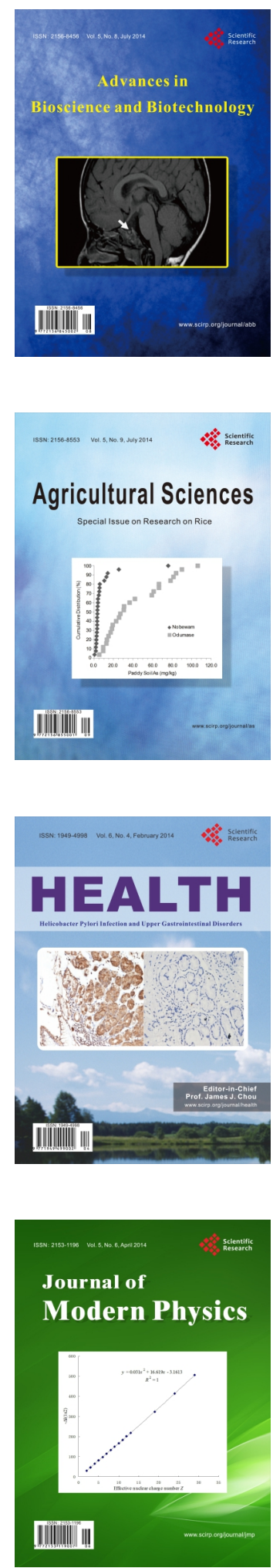
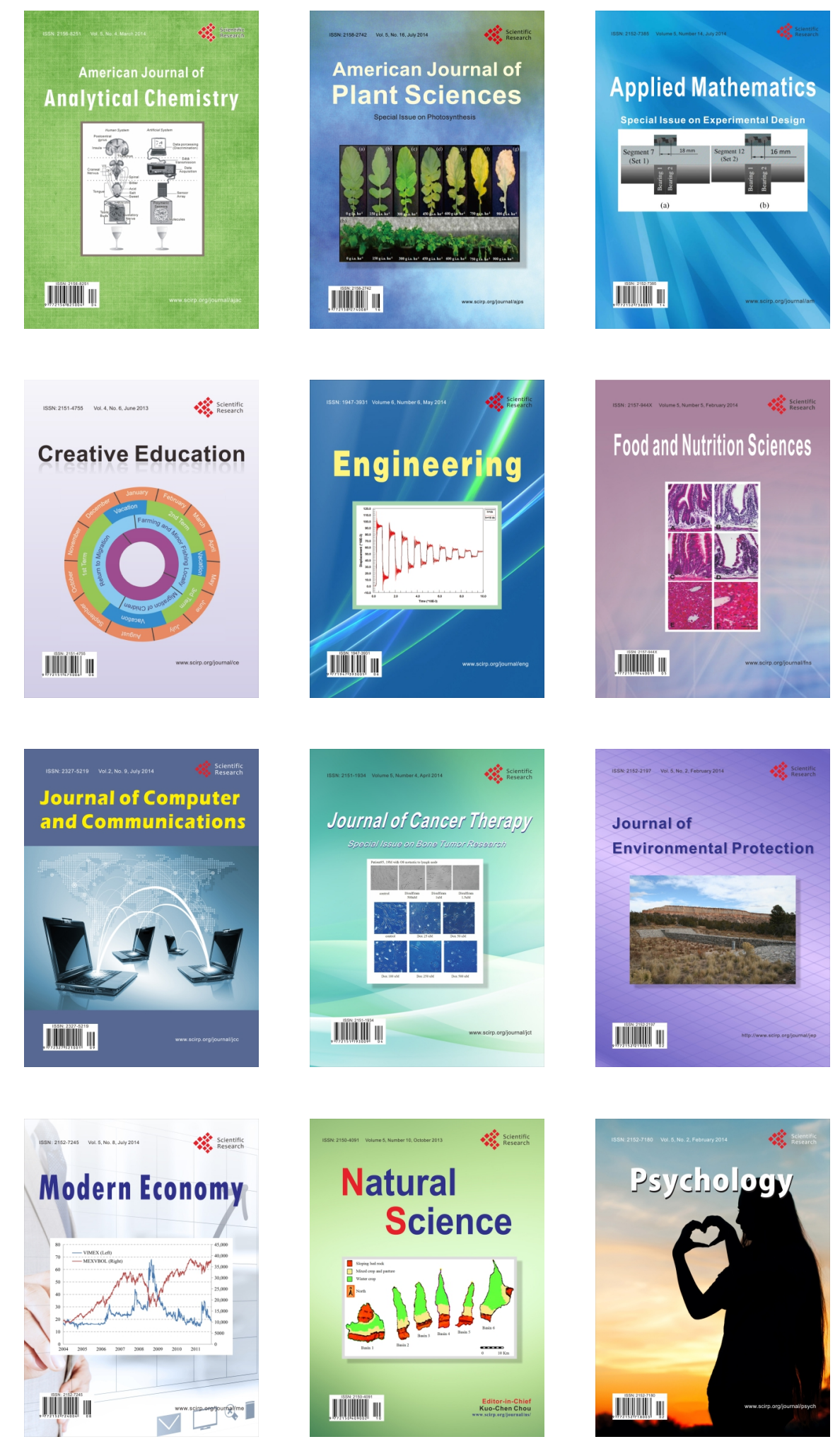